Jablensky, A., Marsella, A. J., Ekblad, S., et al (1992) The International Conference on the Mental Health and Well-being of the World's Refugees and Displaced Persons, Stockholm, Sweden, October 6-11, 1991. Journal of Refugee Studies, 5, 172-184.

Johnson, D. H. (2003) Root Causes of Sudan's Civil Wars. University of Indiana Press.

Lesch, A. M. (1998) The Sudanese Contested National Identities. University of Indiana Press.

Mollica, R. F., Donelan, K., Tor, S., et al (1993) The effect of trauma and confinement on functional health and mental health of Cambodians living in Thailand-Cambodian border camps. JAMA, 270, 581-586.

Paardekooper, B., de Jong, J. T. V. M. \& Hermanns, J. M. A. (1999) The psychological impact of war and the refugee situation on south
Sudanese children in refugee camps in northern Uganda: an exploratory study. Journal of Child Psychology, Psychiatry and Allied Disciplines, 40, 529-536.

United Nations High Commissioner for Refugees (2002) Refugees by Numbers 2001. UN Refugee Agency.

Van Ommeren, M., De Jong, J. T., Sharma, B., et al (2001) Psychiatric disorders among tortured Bhutanese refugees in Nepal. Archives of General Psychiatry, 58, 475-482.

World Health Organization (2004) Retrospective Mortality Survey Among the Internally Displaced Population, Greater Darfur, Sudan, August 2004. Available at http://www.who.int/disasters/repo/14652.pdf. Last accessed 5 November 2006

\title{
Post-traumatic stress disorder among Afghan refugees following war
}

\author{
Khalid A. Mufti, ${ }^{1}$ Farooq Naeem, ${ }^{2}$ Haroon Rasheed Chaudry, ${ }^{3}$ Asad Haroon, ${ }^{4}$ \\ Farida Saifi, ${ }^{4}$ Siama Mahmood Qureshi ${ }^{4}$ and Saif ur Rehman Dagarwal'
}

\author{
'Ibadat Hospital, EE 32 Nishterabad Peshawar, Pakistan, email kamufti2001@yahoo.com \\ ${ }^{2}$ Department of Psychiatry, Royal South Hants Hospital, Southampton SO14 3ED, UK \\ ${ }^{3}$ Fatima Jinnah Medical College, Lahore, Pakistan \\ ${ }^{4}$ Horizon, EE 32 Nishterabad Peshawar, Pakistan \\ ${ }^{5}$ Village Daigam, Distt. Kama City Ningarhar, Afghanistan
}

\begin{abstract}
here was a large influx of Afghan refugees into Pakistan during the 1980s and in particular after the US invasion of Afghanistan in 2001. That refugees have high rates of mental health problems has been well established (e.g. De Jong et al, 2000) - causes include migration, often with painful transit experiences, difficult camp life and the experience of major trauma, including multiple losses of family members as well as the loss of property and traditional lifestyle. However, the Afghan refugees in Pakistan have been poorly studied. Although the mental health problems of Afghan refugees have been studied in the West, the numbers of participants in such research have been relatively small.

The burden of healthcare for Afghan refugees lies mainly with the Pakistani government and non-governmental organisations. The refugees place a further burden on the already poorly financed healthcare system in Pakistan. It is encouraging to note that the host population has shown great courage and patience in support of Afghan refugees.

Many studies in the West have found high rates of psychiatric disorder among refugees (Summerfield, 2001). Wide variations in the rates of these disorders can be attributed to differing cultures and experiences in the groups sampled. Although the concept of post-traumatic stress disorder (PTSD) has been questioned and it has been suggested that rates may have been exaggerated (Watters, 2001), the rates of PTSD have been estimated to be as high as $90 \%$ in psychiatric clinic populations (Silove, 1999).

In a community study of Afghan refugees in The Netherlands, the prevalence of PTSD was found to be 35\% (Gernaat et al, 2002). Similarly, a US study examined the psychological
\end{abstract}

effects of the war in Afghanistan on two groups of young Afghan refugees currently residing in the USA. The investigators found the rates of mental health problems to be higher among the Pashto-speaking population than among the Tajik population (Mghir \& Raskin, 1999). In another US study (Mghir et al, 1995), 38 refugees aged between 12 and 24 years were interviewed with the Structured Clinical Interview for DSM-III-R. Five of the participants met the criteria for PTSD and 11 met the criteria for major depression (13 had either PTSD or major depression or both).

Afghans living in the Western world represent a small proportion of that country's refugees. Pakistan provides a better opportunity for the study of the mental health problems of the larger Afghan refugee population. We undertook a study to measure the prevalence of psychiatric morbidity among Afghan refugees.

\section{Method}

This was a cross-sectional study. Information was collected from Afghan refugees attending a psychiatric service in Peshawar between December 2003 and March 2004. All the refugees attending who fulfilled our inclusion criteria were approached, and all those who consented were included in our study. The inclusion criteria were: being an Afghan refugee, between the ages of 15 and 65 years, attending the psychiatric service and having a diagnosis of a functional psychiatric illness. Those with a diagnosis of learning disability, dementia or organic brain disorder were excluded from the study. 


\section{Measurement of psychopathology}

Psychopathology was measured using the Mini International Neuropsychiatry Interview (MINI; Sheehan et al, 1998). A form to record experiences of trauma was specially designed based on qualitative experiences with ten refugees.

Statistical analyses were carried out using SPSS version 10 for Windows. Both parametric and non-parametric tests were conducted.

\section{Results}

Information was available for 1540 people who attended the psychiatric service during the study period, but 40 were removed from our initial analyses as they did not meet all the inclusion criteria.

The mean age of the sample was 33 years (range 15-64). Other characteristics of the sample are shown in Table 1. A family history of mental illness was reported by $48.8 \%$ $(n=732)$ and $24.9 \%(n=373)$ had a physical disability or

Table 1 Demographic and other descriptive data for the study sample of Afghan refugees $(n=1500)$

\begin{tabular}{|c|c|c|}
\hline & $n$ & $\%$ \\
\hline \multicolumn{3}{|l|}{ Gender } \\
\hline Male & 837 & 55.8 \\
\hline Female & 663 & 44.2 \\
\hline \multicolumn{3}{|c|}{ Marital status of the respondent } \\
\hline Single & 186 & 12.4 \\
\hline Married & 1251 & 83.4 \\
\hline Widowed & 45 & 3.0 \\
\hline Widower & 18 & 1.2 \\
\hline \multicolumn{3}{|l|}{ Level of education } \\
\hline Primary & 232 & 15.5 \\
\hline Matriculation & 17 & 1.1 \\
\hline Uneducated & 1251 & 83.4 \\
\hline \multicolumn{3}{|l|}{ Employment status } \\
\hline Self-employed & 462 & 30.8 \\
\hline Employed & 231 & 15.4 \\
\hline Unemployed & 807 & 53.8 \\
\hline \multicolumn{3}{|l|}{ Children } \\
\hline Up to 2 years & 396 & 26.4 \\
\hline $3-5$ years & 302 & 38.1 \\
\hline 6 years or more & 267 & 33.4 \\
\hline \multicolumn{3}{|l|}{ Migration period } \\
\hline 1 year & 249 & 16.6 \\
\hline 2 years & 1173 & 78.2 \\
\hline 3 years & 78 & 5.2 \\
\hline
\end{tabular}

Table 2 Psychiatric morbidity among the study sample of Afghan refugees $(n=1500)$

$\begin{array}{lrr}\text { Primary diagnosis } & \text { Frequency } & \% \\ \text { None } & 19 & 1.3 \\ \text { Major depressive episode: lifetime } & 63 & 4.2 \\ \text { Major depressive episode: current } & 34 & 2.3 \\ \text { Manic episode: current } & 3 & 0.2 \\ \text { Hypomanic episode: past } & 2 & 0.1 \\ \text { Panic disorder: current } & 27 & 1.8 \\ \text { Obsessive-compulsive disorder } & 5 & 0.3 \\ \text { Post-traumatic stress disorder } & 918 & 61.2 \\ \text { Substance dependence (non-alcohol) } & 163 & 10.9 \\ \text { Substance misuse (non-alcohol) } & 54 & 3.6 \\ \text { Psychotic disorder: lifetime } & 74 & 4.9 \\ \text { Psychotic disorder: current } & 57 & 3.8 \\ \text { Generalised anxiety disorder } & 81 & 5.4 \\ \text { Total } & 1500 & 100.0\end{array}$

Table 3 Frequency of disorders comorbid with post-traumatic stress disorder

\begin{tabular}{lcc|} 
Diagnoses & Frequency & $\%$ \\
None & 573 & 38.2 \\
Major depressive episode: current & 211 & 14.1 \\
Major depressive episode: lifetime & 242 & 16.1 \\
Manic episode: current & 30 & 2.0 \\
Manic episode: past & 16 & 1.1 \\
Panic disorder: current & 47 & 3.1 \\
Social phobia & 6 & 0.4 \\
Substance dependence & 42 & 2.8 \\
Substance misuse & 80 & 5.3 \\
Psychotic disorder: lifetime & 16 & 1.1 \\
Psychotic disorder: current & 76 & 5.1 \\
Generalised anxiety disorder & 161 & 10.7
\end{tabular}

Table 4 Types of trauma experienced: differences between male and female respondents

\begin{tabular}{lrrrr} 
& \multicolumn{2}{c}{ Male } & \multicolumn{2}{c}{ Female } \\
& $n$ & $\%$ & $n$ & $\%$ \\
& 69 & 13.4 & 170 & 42.2 \\
Bombardment & 61 & 11.7 & 88 & 21.8 \\
$\begin{array}{l}\text { Watched a closed relative } \\
\text { being killed }\end{array}$ & & & & \\
Watched other being killed & 36 & 7.1 & 15 & 3.7 \\
Shooting in combat & 39 & 7.6 & 21 & 5.4 \\
Witnessed dead bodies & 38 & 7.3 & 39 & 9.7 \\
Physical assault and torture & 183 & 35.4 & 26 & 6.5 \\
Lost body part owing to blast & 19 & 3.7 & 9 & 2.3 \\
Being held hostage & 61 & 11.9 & 27 & 6.7 \\
Other & 10 & 1.9 & 7 & 1.7 \\
Total & 516 & 100.0 & 402 & 100.0
\end{tabular}

long-term illness. Only $13.1 \%(n=196)$ had contacted health services previously to seek help with a psychiatric illness. Most of the refugees were Pashtun ( $n=1411,94.1 \%)$; other ethnic groups included Uzbek $(n=29,1.9 \%)$, Tajik $(n=20$, $1.3 \%)$, Hazara $(n=12,0.8 \%)$, Turkman $(n=4,0.3 \%)$, Baluch $(n=8,0.5 \%)$ and Kizilbash $(n=16,1.1 \%)$.

Table 2 shows the prevalence of psychiatric disorders and Table 3 the degree of comorbidity. Table 4 shows the frequencies of various types of trauma experienced by this sample according to gender.

\section{Discussion}

Most of the study population were unemployed, married and not formally educated; there were no significant gender differences in these respects. Most had a diagnosis of PTSD, but the rates of depression and anxiety were low. Therefore the rates of comorbid diagnoses indicated that depression and anxiety were distinct. Religious, cultural taboos could be the reason for low substance and alcohol misuse in this group.

Our patients reported a variety of traumatic events. While men reported mainly torture and assault, women were more commonly affected by the direct experience of bombardment. This is possibly because men were more likely to be directly involved in the war, while women remained at home.

The majority of our patients were Pashtuns. In a study conducted in the USA, the investigators found that the rates of psychiatric disorders and of war-related experiences among Afghans from different regions were different. Among the inhabitants of Nangarhar Province, the prevalence rates of both multiple traumatic events and PTSD were high (Scholte et al, 2004). 


\section{Limitations of the study}

There could have been some selection bias, insofar as we studied people attending a mental health service. High rates of PTSD presentation were the core feature of this population. Also, the MINI scale was used to measure PTSD, whereas a more culturally appropriate PTSD scale might have yielded different results.

\section{References}

De Jong, J., Scholte, W., Koeter, M., et al (2000) The prevalence of mental health problems in Rwandan and Burundese refugee camps. Acta Psychiatrica Scandinavica, 102, 171-177.

Gernaat, H. B., Malwand, A. D., Laban, C. J., et al (2002) Many psychiatric disorders in Afghan refugees with residential status in Drenthe, especially depressive disorder and post-traumatic stress disorder. Nederlands Tijdschrift voor Geneeskunde, 146, 11271131.
Mghir, R. \& Raskin, A. (1999) The psychological effects of the war in Afghanistan on young Afghan refugees from different ethnic backgrounds. International Journal of Social Psychiatry, 45, 29-36; discussion 36-40.

Mghir, R., Freed, W., Raskin, A., et al (1995) Depression and posttraumatic stress disorder among a community sample of adolescent and young adult Afghan refugees. Journal of Nervous and Mental Disease, 183, 24-30.

Scholte, W. F., Olff, M., Ventevogel, P., et al (2004) Mental health symptoms following war and repression in eastern Afghanistan. JAMA, 292, 585-593.

Sheehan, D. V., Lecrubier, Y., Sheehan, K. H., et al (1998) Mini International Neuropsychiatric Interview (M.I.N.I.): the development and validation of a structured diagnostic psychiatric interview for DSM-IV and ICD-10. Journal of Clinical Psychiatry, 59 (suppl. 20), 22-33.

Silove, D. (1999) The psychosocial effects of torture, mass human rights violations, and refugee trauma. Journal of Nervous and Mental Disease, 187, 200-207.

Summerfield, D. (2001) Asylum-seekers, refugees and mental health services in the UK. Psychiatric Bulletin, 25, 161-163.

Watters, C. (2001) Emerging paradigms in the mental health care of refugees. Social Science and Medicine, 52, 1709-1718.

\section{Malawi}

The country profiles section of International Psychiatry aims to inform readers of mental health experiences and experiments from around the world. We welcome potential contributors. Please contact Shekhar Saxena (email saxenas@who.int).

\section{Felix Kauye ${ }^{1}$ and Chitsanzo Mafuta ${ }^{2}$}

${ }^{1}$ Chief Government Psychiatrist, Ministry of Health, Zomba Mental Hospital, Zomba, Malawi, email felixkauye@yahoo.com ${ }^{2}$ Registrar Psychiatric Clinical Officer, Ministry of Health, Zomba Mental Hospital, Zomba, Malawi, email chitsanzomafuta@yahoo.co.uk

$\mathrm{M}$ alawi is a country with an approximate area of $118000 \mathrm{~km}^{2}$. Its population is estimated at 13 million and the gender ratio (men per hundred women) is 98 . The proportion of the population under the age of 15 years is $47 \%$ and the proportion above the age of 60 years is $5 \%$. The literacy rate is $75.5 \%$ for men and $48.7 \%$ for women (World Health Organization, 2005).

For administrative purposes, Malawi is divided into three regions, which are further divided into a total of 28 districts. The capital city is Lilongwe, which is situated in the central region, and the main means of travel between the capital and districts is by road.

The main languages used in Malawi are English and Chichewa. The largest ethnic group is Chewa and the other ethnic groups are Nyanja, Tumbuka, Yao, Nkhonde and Ngoni plus the Europeans, Indians and other foreign nationals. The largest religious groups are Christians followed by Muslims.

\section{Health indicators}

Malawi has high rates of infant and maternal mortality rates. The life expectancy at birth is 40 years for both males and females (National Statistical Office of Malawi).

\section{Health services}

There are very few doctors. Clinical officers, medical assistants and enrolled nurses comprise the backbone of Malawian healthcare, but there are shortages of these health personnel, especially in the rural areas, as people prefer to practise in urban areas.

The smallest health unit in Malawi is the 'health post', which is manned by 'health surveillance assistants' (who have 10 weeks' orientation training). Each health post serves a small number of villages. Next in the referral hierarchy is the health centre, which is usually staffed by medical assistants (who have 2 years' training) and nurses. Patients who cannot be treated at the health centre are referred to the district hospitals, which are present in all but 3 of the 28 districts. There are four general tertiary referral hospitals, distributed in all three regions of Malawi, with two in the southern region, which is the biggest.

\section{Mental health resources and services}

Zomba Mental Hospital, which is situated in the southern region, is the only government tertiary psychiatric referral hospital in Malawi. It has 333 beds and on average admits 1500 patients per year. There is a smaller psychiatric unit in the central region, in Lilongwe, with about 30 beds, and this is run as part of Kamuzu Central Hospital, which is the tertiary referral hospital in the central region. Psychiatric patients from the northern region are usually referred to a missionary hospital, St John of God in the city of Mzuzu, which has 50 in-patient beds and which runs an effective 